\title{
Hospital discharge reports: content and design
}

\author{
A J TUlloch, G H FOWLER, J J McMUllaN, J M SPENCE
}

British Medical fournal, 1975, 4, 443-446

\section{Summary}

The information required by family doctors on initial and final discharge reports from hospitals was specified and 546 such reports from hospitals in Aylesbury, Amersham, Banbury, Oxford, and High Wycombe were reviewed for the availability and accessibility of important information.

Several items could have been recorded better, including the name of the hospital, the specialty (or department) concerned, and the name of the consultant in charge of the case. Drug reactions seemed to be under-reported in the initial discharge reports and information about treatment on discharge was inadequate. The recording of the prognosis and information given to the patient was deficient and communication on follow-up needs to be improved. The use of obscure abbreviations was widespread.

There is room for improvement in the ease of access to important information, especially the diagnostic assessment, and the time taken for final reports to reach the general practitioner.

\section{Introduction}

Better communication within the health service has aroused much interest recently, ${ }^{1-6}$ especially now that medical care has become a team responsibility. Hospital discharge reports are one form of communication capable of improvement. We therefore decided to review reports on patients discharged from various hospital departments in the Oxford region. A strictly scientific evaluation of the reports would have obliged us to review each department in turn because of the variation in the work done (and thus the nature of the reports) in different departments. Since we had neither the time nor the resources to do this we decided instead to review discharge reports from a variety of departments so that broad trends could be exposed.

Objectives-These were to specify the information required by the family doctor and to assess the extent to which hospital discharge reports in the study area supplied the information required promptly and acted as a convenient source of reference.

\section{Information required by family doctors}

The importance of accurate, complete, and well-designed hospital discharge reports is often underestimated and we have therefore detailed the optimum layout and content of these reports together with some notes on their value to the family doctor. Having decided on the information that should be incorporated in hospital reports and their layout we conducted our survey of reports in the Oxford area.

\section{IDENTIFYING DATA}

Accurate identification of the patient depends on at least three of the following items being recorded: full name, address, date of birth, hospital number (which is not always available), and National Health Service number.

The name and address of the "usual" family doctor should be recorded rather than the doctor with whom the patient is registered, which may be irrelevant in a group practice. Likewise, it prevents the 
report being sent back to a locum or rota doctor no longer involved with the patient. Furthermore, unequivocal information on the hospital department, the consultant, and the name and status of the reporting doctor makes contact between the family doctor and the hospital much easier. This is especially important in the case of an assistant or locum who is not familiar with the area.

\section{CLINICAL DATA}

The date of admission and discharge are clearly important, but so is the date of the report. A short note on the presenting symptoms is useful because the doctor who sends in the patient may not be the one who receives the report. Furthermore, the details of the case may not be remembered when the report is received three to four weeks after admission.

Diagnostic assessment (however negative) is valuable and needs to be clearly identified to facilitate reference. Abnormal findings on examination or investigation that cannot be explained should be listed alongside the diagnoses so that they are more liable to be kept under careful review. Often they are simply lost in the text of the report and thereafter often conveniently forgotten.

Information about treatment in hospital is valuable but more vital is the treatment on discharge, and a nil return should be made when appropriate to avoid omissions. For the same reason nil returns should be made for drug reactions or the amount of drugs given to the patient.

\section{MANAGEMENT DATA}

Hospital and primary care follow-up information should be clear and easily identifiable in both summaries and final reports. The family doctor should be left in no doubt about what is happening and what is expected of him and his team. Comment on prognosis is clearly desirable in serious illness and it is important to make clear how far the patient has been informed about his condition. In serious illness this is probably the most important information the family doctor needs.

\section{EASE OF ACCESS TO IMPORTANT INFORMATION}

The value of well-designed structured records is often underestimated by doctors, who write purely narrative reports in which important information is given no special emphasis. Clear identification of such data by block capitals, a different coloured type, underlining, or boxing greatly facilitates reference to important information. As a result requests for follow-up by the general practitioner are less likely to be overlooked. The structured format described by Stevenson et $a l^{7}$ meets nearly all the design requirements of the ideal discharge report.

\section{TIME TAKEN FOR REPORTS TO REACH THE GENERAL PRACTITIONER}

An initial summary should arrive within three to four days (at most) of the patient's discharge, and the use of the telephone should be considered when early action by the general practitioner is required. Final reports should arrive as soon as possible and not more than two weeks after the patient's discharge.

\section{Methods}

Eighteen doctors took part in the study. They were asked to review up to 35 consecutive hospital discharge reports reaching them during a 10-week period beginning in May 1974 for the presence or absence of information on the identity of the patient and hospital staff, and on the management given and recommended. They also had to judge the structuring of the report and the ease of access to the diagnostic assessment.

Under "structuring" they were asked to code the reports in one of the following categories: wholly structured, which was defined as being divided completely into marked sections; unstructured, which was taken to describe the essay-style narrative letter in which no data are specially emphasised; or partly structured, which was defined as the essay style letter with certain important data (usually the diag- nosis) highlighted by such means as underlining, the use of block capitals, or boxing.

Estimation of ease of access to the diagnostic assessment depended on whether it was simply part of a narrative report or highlighted in some way so that it was clearly identifiable at a glance. The diagnostic assessment included not only those cases where a firm diagnosis had been made but also those where a precise diagnosis was not possible and the specialist had said so.

Finally, the dates of admission, discharge, and writing of the report were recorded together with the date on which it was received. Table I shows that almost $80 \%$ of the reports came from the Oxford hospitals. The inclusion of the reports from other areas provides a means of comparison with the Oxford results rather than a strict control.

TABLE I-Number of reports analysed according to area of hospitals

\begin{tabular}{|c|c|c|c|}
\hline Area & $\begin{array}{c}\text { Initial } \\
\text { summaries }\end{array}$ & Final reports & Total \\
\hline 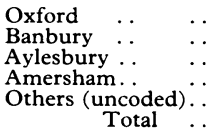 & $\begin{array}{r}201 \\
24 \\
7 \\
19 \\
2 \\
253\end{array}$ & $\begin{array}{r}224 \\
35 \\
12 \\
21 \\
1 \\
293\end{array}$ & $\begin{aligned} & 425(77 \cdot 8 \%) \\
& 59(10 \cdot 8 \%) \\
& 19(3.5 \%) \\
& 40(7.3 \%) \\
& 3(0.6 \%) \\
& 546(100 \%)\end{aligned}$ \\
\hline
\end{tabular}

\section{Results and comment}

\section{IDENTIFYING DATA}

The name and address of the patient and the general practitioner were well recorded and so was the hospital number, except in the Oxford initial summaries, in which it was missing in $30 \%$ of cases. On the other hand, the recording of the patient's age or date of birth was poor, being absent in almost a quarter of the initial summaries and a third of the final reports (table II).

TABLE II-Proportion of 253 initial summaries and 293 final reports in which identifying data were missing

\begin{tabular}{|c|c|c|c|c|c|}
\hline & & \multicolumn{2}{|c|}{$\begin{array}{c}\text { Absent on } \\
\text { initial summaries }\end{array}$} & \multicolumn{2}{|c|}{$\begin{array}{l}\text { Absent on } \\
\text { final reports }\end{array}$} \\
\hline & & No & $\%$ & No & $\%$ \\
\hline $\begin{array}{l}\text { Name of patient... } \\
\text { Address of patient } \\
\text { Hospital number } \\
\text { Date of birth (or age) } \\
\text { Usual GP's name } \\
\text { Hospital attended } \\
\text { Department or specialty } \\
\text { Consultant }\end{array}$ & $\begin{array}{l}\ldots \\
\because \\
\cdots \\
\cdots \\
\cdots\end{array}$ & $\begin{array}{r}2 \\
6 \\
28 \\
60 \\
20 \\
7 \\
94 \\
35\end{array}$ & $\begin{array}{r}0 \cdot 8 \\
2 \cdot 4 \\
11 \cdot 1 \\
23 \cdot 7 \\
7 \cdot 9 \\
2 \cdot 8 \\
37 \cdot 2 \\
13 \cdot 8\end{array}$ & $\begin{array}{r}0 \\
3 \\
15 \\
96 \\
19 \\
32 \\
69 \\
68\end{array}$ & $\begin{array}{r}0 \\
1 \cdot 0 \\
5 \cdot 1 \\
32 \cdot 8 \\
6 \cdot 5 \\
10 \cdot 9 \\
23 \cdot 6 \\
23 \cdot 2\end{array}$ \\
\hline
\end{tabular}

The name of the hospital was generally well recorded except in the Oxford final reports, in which it was absent in almost $14^{\circ}{ }_{0}$ of cases.

The recording of the department or specialty and the consultant involved was uniformly poor, especially in the letters from peripheral hospital. These omitted to mention the department or specialty in over $50^{\circ}{ }_{o}$ of initial summaries and the name of the consultant in more than a third of final reports.

Hospital staff are probably unaware of the inconvenience caused by the poor standard of recording of the last two items if the general practitioner has to clarify, amplify, or question information given in the report, especially if the doctor is new to the area or a locum.

\section{CLINICAL DATA}

The low rate of recording the presenting symptoms, examination findings, and investigation results was to be expected in the initial summaries, but the recording of those items in the final reports was lower than expected (table III). This was especially so in the peripheral hospitals, $40^{\circ}$ of which did not report the results of investigations. This may reflect the low rate of investigation to be expected in 
TABLE III-Clinical information not given in 253 initial and 293 final reports

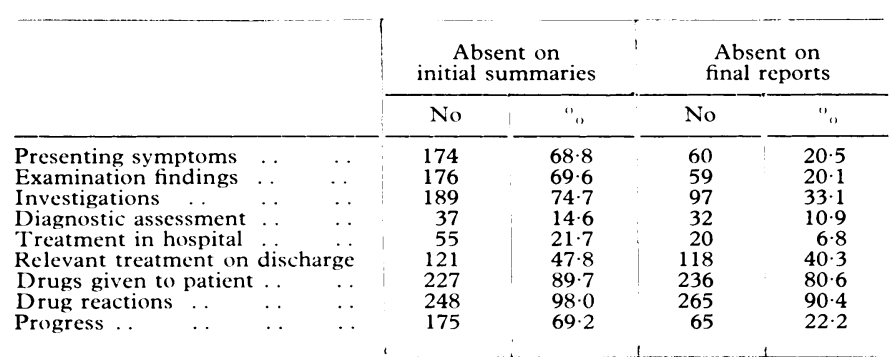

certain hospital departments-for example, for ear, nose, and throat or obstetric cases.

No diagnostic assessment had been attempted in $14^{\prime \prime}$, of initial summaries and almost $11^{\prime \prime}$ "of final reports. It is often valuable to the family doctor if an experienced consultant gives an opinion (when possible) about the most likely diagnosis or states that even a provisional diagnosis is not possible on the information available.

No reference was made to treatment on discharge in almost half of the initial summaries and in $40^{\circ}$ "of the final reports. Every hospita discharge report should contain a section on this item, with nil returns being made where appropriate.

There was no record of drugs supplied by the hospital to the patient on discharge in $90^{\circ}$ " of initial summaries and $80^{\circ}$ " of fina reports. It is important that the family doctor is left in no doubt about how soon the patient's treatment will need to be renewed and it is especially important that this information is recorded in the initial reports.

Drug reactions were reported in only $2^{\prime \prime}$ " of initial summaries and almost $10^{\circ}$ " of final reports. These two sets of reports did not refer to the same patients. Schimmel ${ }^{\times}$and Hurwitz and Wade ${ }^{9}$ both recorded drug reactions in $10^{\prime \prime}$, of patients under care in hospital so that side effects were probably under-reported in the initial discharge reports. In view of the importance of recording and reporting drug reactions a boxed section on drug reactions should be part of every discharge report, and even negative reports should be recorded.

\section{MANAGEMENT DATA}

The initial summaries made no reference to hospital follow-up in $30^{\circ}$ " of cases and primary care action in $77^{\circ}$ " of cases. On the final reports these items were somewhat better recorded, the figures being $23^{\circ}$. and $70^{\circ}$, respectively. Clearly, since the treatment is being shared between the hospital and family doctors it is important the latter is kept informed about proposed hospital follow-up. Furthermore, when action is required by the primary care team it is important that the initial report should indicate this clearly.

About $90^{\prime \prime}$ of the initial summaries and $74^{\circ}{ }^{\circ}$ of the final reports made no comment on the prognosis (table IV). Oxford reports were significantly better in this respect than those from the peripheral hospitals. It is important for the family doctor to know what prognosis has been given to the patient, especially in the case of serious disease. A conflict of opinion simply undermines the patient's faith in his medical advisers. No reference was made to the information given to the patients in $92^{\circ} \%$ of both initial and final reports. Moreover in the initial summaries from the peripheral hospitals this item was only recorded in $2^{\circ}$ " of cases.

TABLE IV-Management data not given in 253 initial and 293 final reports

\begin{tabular}{|c|c|c|c|c|c|}
\hline & & \multicolumn{2}{|c|}{$\begin{array}{c}\text { Absent on } \\
\text { initial summaries }\end{array}$} & \multicolumn{2}{|c|}{$\begin{array}{c}\text { Absent on } \\
\text { final reports }\end{array}$} \\
\hline & & No & ". & No & ${ }^{\prime \prime}$ \\
\hline $\begin{array}{l}\text { Hospital follow-up } \\
\text { Primary care action } \\
\text { Prognosis } \quad . \\
\text { Information given to patient } \\
\text { Status of reporting doctor } \\
\text { Identity of reporting doctor }\end{array}$ & $\begin{array}{l}\cdots \\
\cdots \\
\cdots \\
\cdots \\
\cdots\end{array}$ & $\begin{array}{r}75 \\
195 \\
227 \\
233 \\
36 \\
121\end{array}$ & $\begin{array}{l}29 \cdot 6 \\
77 \cdot 1 \\
89 \cdot 7 \\
92 \cdot 1 \\
14 \cdot 2 \\
47 \cdot 8\end{array}$ & $\begin{array}{r}67 \\
207 \\
218 \\
270 \\
17 \\
21\end{array}$ & $\begin{array}{r}22 \cdot 9 \\
70 \cdot 7 \\
74 \cdot 4 \\
92 \cdot 2 \\
5 \cdot 8 \\
7 \cdot 2\end{array}$ \\
\hline
\end{tabular}

In almost $50 \%$ of initial summaries the doctor reporting had either not signed the letter or his signature was illegible. Among the periph- eral hospitals this figure reached almost $70^{\circ}{ }_{0}$. When a query arises it is therefore often difficult to contact the doctor concerned.

\section{EASE OF ACCESS TO IMPORTANT INFORMATION}

A measure of the ease of access to important information was the degree of structuring of the reports. Altogether $72^{\circ}{ }_{\circ}$ of the initia summaries were fully structured and highlighted important data compared with $58^{\circ}{ }_{\circ}^{\circ}$ of the final reports (table V). The initial summaries from peripheral hospitals were structured six times as often as those in the Oxford area. Hospital doctors who continue to make narrative reports were apparently unaware of how much easier it is to refer to important data in structured reports.

Access to the diagnostic assessment was not clearly identifiable at a glance in almost $20^{\circ}{ }^{\circ}$ of the initial summaries and $28^{\circ}{ }_{\circ}$ of the final reports. The Oxford reports were better in this respect than those from the peripheral hospitals despite the fact that they were more often unstructured. This seems to suggest that either the peripheral hospitals design was unsatisfactory or that structuring is not the whole answer.

Almost two-thirds of the initial summaries and one-third of the final reports were undated and Oxford final reports were undated twice as often as those from the peripheral hospitals.

TABLE $\mathrm{v}$-Structuring of reports and access to diagnostic assessment in initial and final reports

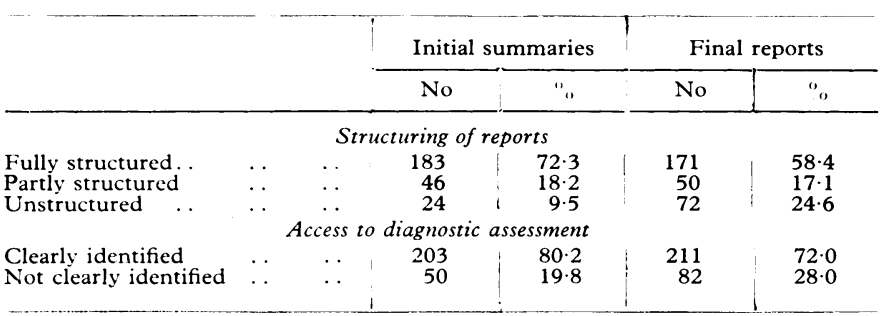

TIME TAKEN FOR REPORTS TO REACH DOCTOR

The initial summary was received on average 4.3 days after the patient's discharge, while the final report arrived 19.4 days after the patient left hospital. Evans and $\mathrm{McBride}^{10}$ in Stratford-upon-Avon received their initial reports an average of 3.7 days and final reports an average of 15.2 days after discharge, while Lockwood and $\mathrm{McCallum}^{3}$ found in an Edinburgh practice that the average time taken for final reports to reach them after the patient's discharge from hospital was 10.6 days.

\section{ABBREVIATIONS}

During the study it emerged that there was a widespread use of abbreviations that were often difficult and sometimes impossible to interpret. The following were collected during the study by one of us (AJT): IDK (internal derangement of knee joint), TIA (transient ischaemic attack), PTA (post traumatic amnesia), BAPAWO (bilateral antral puncture and washouts), SR (sinus rhythm), RBBB (right bundle-branch block), TOP (termination of pregnancy), HCG (human chorionic gonadotrophin), HFFD (high fetal forceps delivery), PFR (peak flow rate, pelvic floor repair), SVD (spontaneous vertex delivery), VPC (ventricular premature beats), LUQ (left upper quadrant), RDS (respiratory distress syndrome), EMU-ZNS-AFB (early morning urine-Ziell Nielsen stain for acid fast bacilli), AIH (artificial insemination from husband), BIPP (bismuth subnitrate and iodoform paste), BSO (bilateral salpingo-oophorectomy), RUQ (right upper quadrant), COAD (chronic obstructive airways disease), RGA (retrograde amnesia), PTI (prothrombin index), AWO (antral washout), BSOM (bilateral suppurative otitis media), TUR (transurethral resection), PNO (principal nursing officer), PID (prolapsed intravertebral disc, pelvic inflammatory disease, peripheral ischaemic disease), SOB (short of breath), PNS (peripheral nervous system), SFD (simple forceps delivery), O/D (outpatients department), IG-TN (ingrowing toenails), EHL (effective half-life), TTO (to take out (drugs))

It would be interesting to know how many doctors (including house staff) could interpret these abbreviations with certainty out of context, which is the only true test of the comprehensibility of an abbreviation. 


\section{Conclusions}

Obviously there is much room for improvement in hospital discharge reports, both in the type and amount of information recorded and in the presentation of this information. The data that family doctors find important is accurate identification of patient and consultant, a diagnostic assessment, information on drug reactions and treatment on discharge, and, possibly most important in the case of seriously ill patients, a note on how far the patient has been informed about his prognosis-should not be lost among narrative but should be immediately identifiable.

We thank the following doctors for collecting the data for this study: G T Bungay, S M King, A C Markus, D M McLennan, R S Pinches, A N Redington, A M Semmence, M G Sheldon, G T Smith, A M Steel, R H Stephenson, J M Talbot, P L Tate, and S D Turner. We also thank $\mathrm{Dr} R \mathrm{M}$ Mayon-White and
Dr A M Semmence for help with the preparation of the paper.

\section{References}

1 Skeet, M, Home from Hospital. London, The Dan Mason Nursing Research Committee, National Florence Nightingale Memorial Committee of Great Britain and Northern Ireland, 1970.

2 Forsythe, G, and Logan, R F L, Gateway or Dividing Line. Oxford, Oxford University Press, 1968.

${ }^{3}$ Lockwood, E, and McCallum, F M, Health Bulletin, 1970, 28(2), 75.

${ }^{4}$ Farrow, S C, Communication Study between The London Hospital and General Practitioners in Tower Hamlets. Operational Research Department Evaluation Report No. 31 (private communication).

${ }^{5}$ Long, A F, and Atkins, J B, British Medical fournal, 1974, 4, 456.

${ }^{6}$ Fletcher, C M, Communication in Medicine. London, Nuffield Provincial Hospitals Trust, 1973.

7 Stevenson, J G, Boyle, C M, and Alexander, W D, Lancet, 1973, 1, 928.

${ }^{8}$ Schimmel, E M, Annals of Internal Medicine, 1964, 60, 100.

9 Hurwitz, N, and Wade, O L, British Medical fournal, 1969, 1, 531.

10 Evans, E O, McBride, K, Fournal of the Royal College of General Practitioners, 1968, 16, 294.

\title{
Occasional Survey
}

\section{Medical care of homeless and rootless young people}

\author{
H M HOLDEN
}

British Medical fournal, 1975, 4, 446-448

Attention has recently been drawn to the plight of the many homeless young people who drift into our big cities. Though the problem is by no means new ${ }^{2}$ it is only within the past 10 years that much public concern has been expressed about them. ${ }^{34}$ The problems of homelessness among the young are immense and raise major social issues which are outside the scope of this paper. I would like to focus on some specifically medical aspects of the problem.

Davies drew attention to the inadequacy of medical care for the homeless in her report The Provision of Medical Care for the Homeless and Rootless. ${ }^{5}$ Unfortunately most of our social institutions, including the NHS, are geared towards a geographically stable population living in flats or houses. Nomadsbe they gipsies, itinerant fairground stall holders, or just dropouts-are deviant and therefore unpopular both with the general public and the institutions which serve them. The homeless tend to be regarded with suspicion and often disgust and, since they have no homes, they are unable to register with a general practitioner. Although they are frequently seen in hospital casualty departments they are unpopular there also and usually got rid of as soon as possible.

This paper is a short account of my experience as a physician to an experimental scheme providing accommodation for homeless and rootless young people in North London.

\section{The scheme}

The scheme was an off-shoot of a detached youth project (the

Skelton, Cleveland

H M HOLDEN, BM, MRCPSYCH, general practitioner
Soho Project) set up in 1968 to explore the needs of the thousands of young people who, at that time, thronged the Soho discotheques and coffee bars every night. In another paper ${ }^{6}$ I have pointed out that, while a degree of alienation is a common and indeed a necessary feature of adolescence, many of these homeless and rootless youngsters had gone beyond the point of no return and were very much at risk.

In 1970 an attempt was made to provide acceptable accommodation for some of these youngsters, and a house was bought in North London offering accommodation to about a dozen young people of both sexes, either singly or in pairs. The accommodation was in a small terraced Victorian house in a once residential area which had become run-down in the ' $50 \mathrm{~s}$ and ' $60 \mathrm{~s}$ because of the threat of major road development. Six rooms were let out as bedsitters, either to individuals or to pairs. The residents were expected to pay a small rent (and sometimes did) and they were obliged to do their own catering and cooking in a communal kitchen. No meals were provided. There were also communal washing and toilet facilities.

The staff of three or four worked chiefly in a communal groundfloor office, which was usually full of people (workers, residents, and visitors) and they saw their main job as being "available" to the residents when required in whatever way they felt to be appropriate. The tasks taken on by the staff were largely self-appointed and varied greatly from one worker to another. Like their clients they were usually young and somewhat deviant-constructive rebels who felt alienated from the establishment but nevertheless quite able to cope with society. All were intensely caring people. Some were qualified social workers; others had no formal qualifications, but since the house was new and experimental there could be no clear job specification. A management support group was available and a consultant met with them regularly to help them conceptualise their task. Despite this the staff turnover was high. The frustrations of the work were great and the inevitable pain of watching young people slowly destroy themselves and of being unable to help them became intolerable. Few stayed longer than a year.

The residents varied in age from 17 to 30 , and in number from eight to ten. Some stayed only a few weeks, others for months or even years. Nearly all came from deprived backgrounds and most could be described as "damaged," having a very limited capacity for making satisfying personal relationships, working, or indeed getting any pleasure out of life except through drugs. Most were registered nar- 